\title{
PROTECTIVE EFFECT OF ETHANOLIC ROOT EXTRACT OF COMMIPHORA CAUDATA AGAINST DIABETIC-INDUCED RATS IN HIGH-FAT DIET-STREPTOZOTOCIN MODEL
}

\author{
ANITHA K ${ }^{1 *}$, SABAPATHI MOHANA LAKSHMI², SATYANARAYANA SV ${ }^{3}$ \\ ${ }^{1}$ Research Scholar, Department of Pharmacology, JNTUA, Ananthapuramu, Andhra Pradesh, India. ${ }^{2}$ Department of Pharmacognosy, Sree \\ Vidyanikethan College of Pharmacy, Tirupati, Andhra Pradesh, India. ${ }^{3}$ Director of Evaluation, JNTUA, Anantapuramu, Andhra Pradesh, \\ India. Email: kuttiappananitha@gmail.com
}

Received: 08 January 2019, Revised and Accepted: 18 January 2019

ABSTRACT

Objective: The present study was to explore the phytochemical analysis and antidiabetic potential of the root of Commiphora caudata in high-fat diet (HFD) streptozotocin-induced diabetic rats.

Methods: The ethanolic root extract of $C$. caudata at a dose of $400 \mathrm{mg} / \mathrm{kg}$ and $200 \mathrm{mg} / \mathrm{kg}$ was administered to diabetic rats. Glibenclamide (5 mg/ $\mathrm{kg}$ ) was used as standard drug.

Results: The data were statistically assessed using one-way ANOVA followed by Dennett's multiple comparison tests. To unfold the mechanism, we studied all the biochemical parameters glucose, total cholesterol, triglycerides (TG), high-density lipoproteins (HDL), low-density lipoproteins (LDL), and very LDL (VLDL) and histopathological examination of the pancreatic tissue section. The ethanolic extracts of root of $C$. caudata showed significant reduce of the level of cholesterol, TG, LDL, VLDL, and significant increase in the serum level of HDL at $400 \mathrm{mg} / \mathrm{kg}$ rather than $200 \mathrm{mg} / \mathrm{kg}$.

Conclusion: Further studies should look into the characterization and isolation of the constituents to know the exact mechanism of hypoglycemic activity. Statistical analyses of this screening method confirm that the proposed method is appropriate and it can be expected to improve basic idea to the researcher who is working in area-like antidiabetic activity.

Keywords: Commiphora caudata, Glibenclamide, High-fat diet streptozotocin, Cholesterol, Triglycerides, Low-density lipoproteins, and Very low-density lipoproteins.

(C) 2019 The Authors. Published by Innovare Academic Sciences Pvt Ltd. This is an open access article under the CC BY license (http://creativecommons. org/licenses/by/4. 0/) DOI: http://dx.doi.org/10.22159/ajpcr.2019.v12i3.31083

\section{INTRODUCTION}

Diabetes mellitus (DM) is a complex metabolic syndrome characterized by either deficiency of insulin production or showing resistance toward insulin. Type $2 \mathrm{DM}$ is a condition in which cells fail to respond to insulin property [1]. As the disease progresses a lack of insulin, formerly called as noninsulin-dependent DM or adult-onset diabetes.

Commiphora caudata is a deciduous tree growing from 12 to $20 \mathrm{~m}$ tall. The bole can be $15-25 \mathrm{~cm}$ in diameter. The tree is sometimes harvested from the wild for local medicinal use. It is occasionally used as an avenue tree and is often planted as an ornamental. The endosperm obtained from four or five fresh or dried seeds is taken two times a day for 2-3 days to relieve stomach ache [2]. The heartwood is gray with darker streaks; the sapwood is white. In addition, these major compounds extracted from seeds of $C$. caudata have important pharmacological effects, thereby aiding in the understanding of the physiology of organisms and in the treatment of various pathologies $[3,4]$. It is claimed to possess astringent, sweet, cooling, aphrodisiac, diuretic, and antidiabetic activities. It is used for fever, strangury, the leaves are useful in rheumatalgia $[5,6]$. By considering all the facts, the purpose of the present study was to unlock the antidiabetic activity of the $C$. caudata in the high-fat diet (HFD) streptozotocin (STZ)-induced rats.

\section{METHODS}

Plant material and authentication

Roots of $C$. caudata was collected in November from Tirumala hills, Chittoor district of Andhra Pradesh and authenticated by Professor N. Yasodamma, Department of Botany, Sri Venkateswara University, Tirupati, India and compared to that of the standard Herbarium SVUTY, Department of botany with specimen voucher.
Chemicals and reagents

STZ, glibenclamide (GLB), and the biochemical estimation kits were procured from Aldrich Sigma Ltd., Bangalore.

\section{Extraction}

Collected roots were shade dried; powdered and crude substance $500 \mathrm{~g}$ was taken and subjected to run in Soxhlet apparatus for $72 \mathrm{~h}$ with ethanol as a solvent, respectively. The extract obtained was concentrated in Rotary flask evaporator under reduced pressure at $65^{\circ} \mathrm{C}$; yield was found to be $4.89 \%$ and stored in the desiccators for the further use.

\section{Preliminary phytochemical screening}

The ethanolic root extract of Commiphora caudate (EECC) was subjected to preliminary phytochemical analysis for the detection of various phytoconstituents such as alkaloids, glycosides, saponins, flavonoids, tannins, phenolic compounds, triterpenoids, carbohydrates, and proteins using standard procedures as per mentioned $[7,8]$.

\section{Experimental animals}

The male albino Wistar rats weighing between 180 and 200 g were taken for the study which were procured and maintained in a wellventilated room with 12:12 h light/dark cycle in polypropylene cages. Standard pellet feed (hindustan lever ltd., bangalore) and drinking water was provided ad libidum throughout the experimentation period. Rats were acclimatized to laboratory conditions 1 week before the initiation of experiments. Ethical Committee clearance was obtained from the Institutional Animal Ethical Committee (IAEC) of Committee for Control and Supervision of Experiments on Animals and bearing SVCP/IAEC/2018. 
Acute toxicity studies

As per OECD 423 guidelines, the EECC was administered to albino Wistar rats by oral route starting from $5 \mathrm{mg} / \mathrm{kg}$ to $2000 \mathrm{mg} / \mathrm{kg}$. The animals were monitored for any changes in fur falling, eyes, sign of tremors, lethargy, motor activity, and itching, behavioral parameters continuously, observed for lethality and desired dose of $400 \mathrm{mg} / \mathrm{kg}$ and $200 \mathrm{mg} / \mathrm{kg}$ was selected [9].

\section{Experimental design}

The experimental design comprised five groups each consisting of five rats fed by normal standard pellet for acclimatization then 2 weeks of dietary manipulation, the groups of rats were fed by HFD and the administration was continued for 21 days and on the $21^{\text {st }}$ day STZ $(45 \mathrm{~g} / \mathrm{kg}$ ) was administered and the fasting blood glucose was measured before and after 3 days after the vehicle or STZ injection. $20 \%$ glucose was administered after $4 \mathrm{~h}$ of STZ injection and ethanolic extract of $C$. caudata low dose and high dose was continued for 21 days after STZ injection [10]. The rats with the fasting blood glucose $\geq 200 \mathrm{mg} / \mathrm{dl}$ were considered diabetic and selected for further pharmacological studies. Group I: Normal control (NC) rats were administered $0.1 \%$ CMC in saline daily (NC). Group II: Diabetic rats were administered HFD + STZ (45 mg/kg). Group III: Diabetic control rats were administered HFD + STZ $(45 \mathrm{mg} / \mathrm{kg})$ and GLB (5 mg/kg). Group IV: Diabetic control rats were administered HFD + STZ (45 mg/kg) and EECC (200 mg/kg per body weight $[B W])$. Group V: Diabetic control rats were administered HFD + STZ (45 mg/kg) and EECC (400 mg/kg per BW). BW was measured weekly. At the end of the experimental period, the diets were removed from the cages $12 \mathrm{~h}$ before the animals were euthanized [11]. Blood samples were collected by the retroorbital method and centrifuged to obtain serum after the collection of blood, the rats were euthanized, and liver, pancreas, and kidney were excised immediately, rinsed with phosphate buffer saline, and weighed [12]. The samples were undergone for biochemical estimations and pancreas was stored in $10 \%$ formalin solution for histopathological studies.

\section{Measurement of body weight of the rats}

Initial and final BW of the rats was measured using weighing machine and the data obtained was represented.

\section{Measurement of biochemical parameters}

Determination of the serum biochemical parameters such as the total cholesterol (TC), triglycerides (TG), high-density lipoproteins (HDL), low-density lipoproteins (LDL), and very LDL (VLDL) were measured using the commercially available standard kits [13] according to the instructions and the results were calculated as per the formula.

\section{Histopathalogical studies}

After inducing diabetic condition, rat from each group were anesthetized and pancreas was removed from the abdominal region of each rat and was excised quickly and fixed in $10 \%$ bufferedformaldehyde at room temperature [14]. After dehydration using graded ethanol, pieces of tissues were embedded in paraffin; $5-\mu \mathrm{m}$ thick sections were cut by a rotator microtome and mounted on glass slides. Sections were then deparaffinized with xylene, counterstained with hematoxylin and eosin [15]. After the tissue sections were stained with hematoxylin and eosin and then viewed were examined using Olympus BX51 microscope model U-LH100HG and the results were shown. The normal architecture and the damaged architecture were studied of liver, pancreas, and kidney was assessed and analyzed in all the histopathological sections.

\section{Statistical analysis}

The statistical analysis was carried out using the latest Graph pad prism software. All values were expressed as mean \pm standard error of the mean. Data analysis was performed by one-way ANOVA followed by Dunnett's multiple comparison tests. Difference level at $\mathrm{p}<0.05$ was considered a statistically significant condition.

\section{RESULTS AND DISCUSSIONS}

\section{Preliminary phytochemical analysis}

The phytochemical screening of EECC was revealed the presence of flavanoids, terpenoids, saponins, proteins, alkaloids, and these chemical constituents was responsible for different therapeutic actions and results were represented in Table 1.

\section{Effect of extracts on body weights}

Effect of EECC on BWs in all the groups. The BW of the control group increased significantly from $222 \pm 2.24$ to $259 \pm 0.98$. The diabetic rats showed a significant decrease in BW from $219 \pm 0.78$ to $168 \pm 01.2$. After treatment with the EECC and GLB, there was no statistical significance and slight change in the BWs was observed in Fig. 1.

\section{Effect of extract on serum blood glucose}

The effect of EECC was investigated for its hypoglycaemic potential in normal, diabetic, and extracts treated groups. The EECC at a dose of $200 \mathrm{mg} / \mathrm{kg}$ and $400 \mathrm{mg} / \mathrm{kg}$ for 21 days of administration showed a significant decrease in blood glucose compared to that of diabeticinduced rats in Fig. 2

Table 1: Preliminary phytochemical analysis of ethanolic root extract of Commiphora caudata

\begin{tabular}{ll}
\hline Chemical tests & Inference \\
\hline Test for carbohydrates & + \\
Test for alkaloids & - \\
Test for proteins & + \\
Test for glycosides & - \\
Test for flavanoids & + \\
Test for terpenoids & + \\
Test for resins & - \\
Test for tannins & - \\
\hline
\end{tabular}

+: Presence, -: Absence

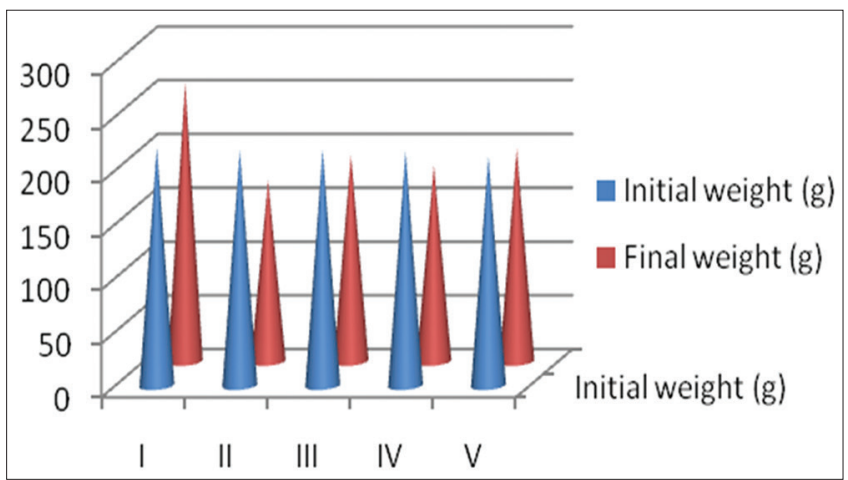

Fig. 1: Effect of extracts on body weights of rats

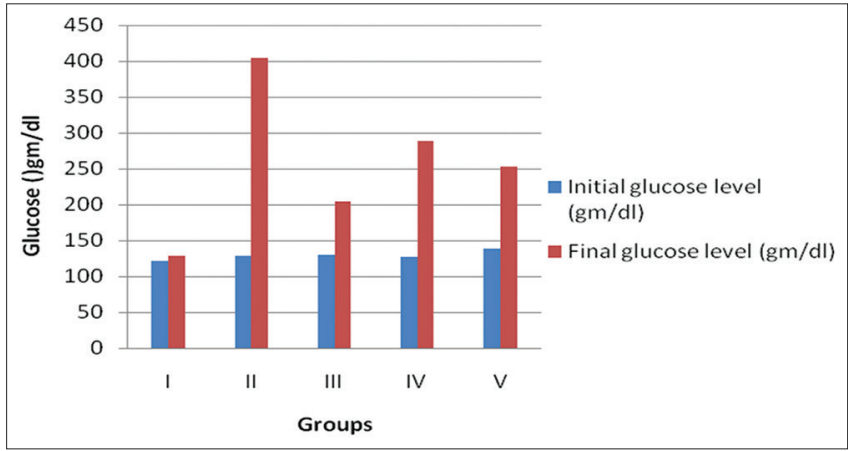

Fig. 2: Effect of extract on serum blood glucose levels 
Effect of extract on lipid profile

In the present study, HFD + STZ significantly increased the TC, TG, LDL, VLDL levels and decreased the level of HDL compared to control groups. Flavonoids present in the extract have been reported to decrease LDL and increase HDL and it also helps in the removal of cholesterol from peripheral tissues to the liver for catabolism and excretion $[16,17]$. Hence, the decrease in levels of TC, TG, LDL, and increase the level of HDL depicted in the present study may be due to the presence of effects of chemical constituents in EECC. Standard treated group showed marked significantly decreased levels of lipid levels and increased level of HDL [18]. After administration of EECC extracts of $400 \mathrm{mg} / \mathrm{kg} \mathrm{b}$. w. and $200 \mathrm{mg} / \mathrm{kg} \mathrm{b}$. w for 21 days it reduced the TC, TG, LDL, VLDL levels and increased level of HDL in diabetic rats compared to control groups and thus showed significant hypoglycemic potential and the results were calculated as per the formula and depicted in Fig. 3.

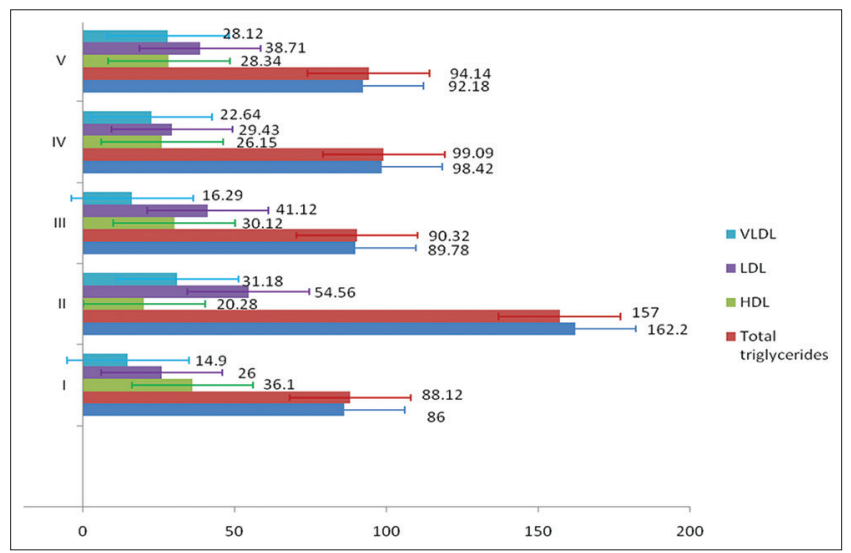

Fig. 3: Effect of ethanolic root extract of Commiphora caudate in high fat diet + streptozotocin induced rats on different lipid levels, concentration expressed as $\mathrm{mg} / \mathrm{kg}$
Histopathological studies

Effect of EECC on pancreas showing the architecture is represented in Fig. 4.

\section{DISCUSSION}

In the present study, the initial attempts were directed toward finding the glucose lowering effect of ethanolic extracts of roots of $C$. caudata in HFD + STZ-induced diabetic rats and further sensitive for pharmacological testing. The HFD rat model with a dose of STZ $(45 \mathrm{mg} / \mathrm{kg})$ thus can be more considered to represent the path physiological state of type 2 diabetes and was accompanied by the characteristic of diabetic condition produced by high dose of STZ $[19,20]$. Hence, HFD in combination with low dose of STZ $(45 \mathrm{mg} / \mathrm{kg})$ was chosen for generating the rat model for further studies. The data obtained showed that the plasma levels of TG, TC, and LDL in HFD + STZ fed rats were significantly higher than those of control group; however, plasma HDL levels were significantly decreased, indicating that HFD + STZ feeding caused hyperglycaemic in rats $[21,22]$. After the treatment of extract in the experimental period, it significantly decreased these changes in plasma levels of TG, TC, and LDL and increased HDL levels induced by HFD + STZ in different groups $[23,24]$. The EECC showed significant as the antidiabetic potential at $400 \mathrm{mg} / \mathrm{kg}$ rather than $200 \mathrm{mg} / \mathrm{kg}$. So by this HFD + STZ induced model the ethanolic extract of roots of C. caudata has shown the significant changes in lipoprotein levels that depicts that the extract possesses the antidiabetic activity.

\section{CONCLUSION}

The EECC of two different doses $400 \mathrm{mg} / \mathrm{kg}$ and $200 \mathrm{mg} / \mathrm{kg}$ have shown the significant potential against the diabetic condition in the HFD + STZinduced model. Compared to $200 \mathrm{mg} / \mathrm{kg}$ dose, $400 \mathrm{mg} / \mathrm{kg}$ showed the better significance of hypoglycemic potential. Further studies should keep an eye toward the characterization, isolation to know the exact mode of the mechanism of the hypoglycemic potential of roots of C. caudate.

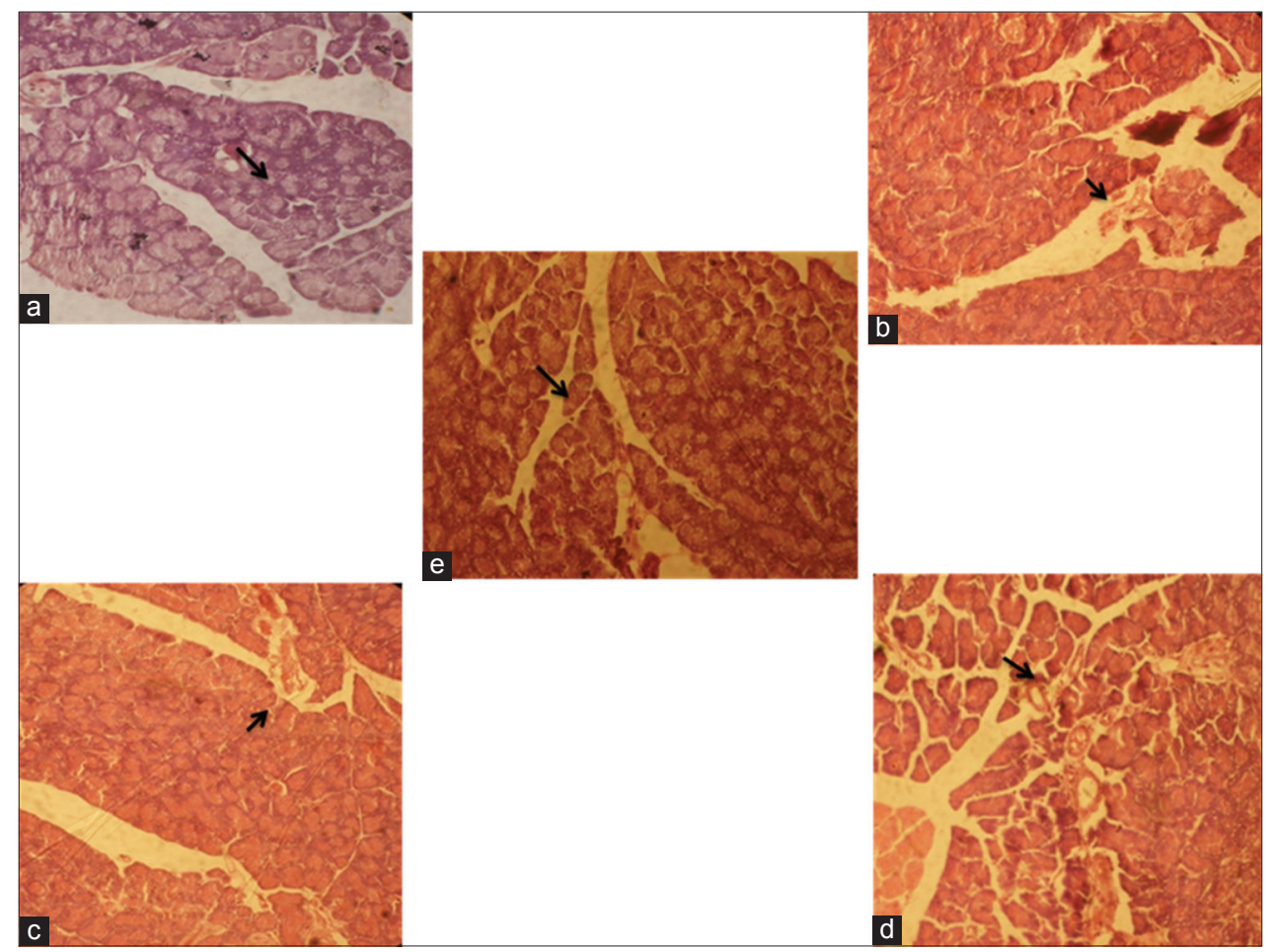

Fig. 4: Photographs of the histopathological tissue sections (a) control group eliciting the normal pancreas architecture (b) negative control group showing the complete damage of pancreas architecture (c) positive control group showing the recovery of damaged pancreas architecture (d) low dose treated group showing the recovery of damaged pancreas architecture to some extent (e) high dose treated group showing the recovery of damaged pancreas architecture to a significant extent 


\section{ACKNOWLEDGMENT}

Corresponding authors show gratitude toward the Chairman and Principal of Sree Vidyanikethan College of Pharmacy, A. Rangampet, Chittoor district of Andhra Pradesh for their Support and facilities provided to fulfil this research work.

\section{AUTHORS' CONTRIBUTIONS}

Performed the Experiment: Kuttiappan Anitha Project guided: Dr. S. Mohana Lakshmi and Prof. S. V. Satyanarayana Wrote the paper: Kuttiappan Anitha. Revised the Article: Kuttiappan Anitha.

\section{CONFLICT OF INTEREST STATEMENT}

We don't have the conflict of interest.

\section{REFERENCES}

1. Moneva MH, Dagogo-Jack S. Multiple drug targets in the management of type 2 diabetes. Curr Drug Targets 2002;3:203-21.

2. Wild S, Roglic G, Green A, Sicree R, King H. Global prevalence of diabetes: Estimates for the year 2000 and projections for 2030. Diabetes Care 2004;27:1047-53.

3. Yamada K, Nakata M, Horimoto N, Saito M, Matsuoka H, Inagaki N, et al. Measurement of glucose uptake and intracellular calcium concentration in single, living pancreatic beta-cells. J Biol Chem 2000;275:22278-83.

4. Dhar ML, Dhar MM, Dhawan BN, Mehrotra BN, Ray C. Screening of Indian plants for biological activity: I. Indian J Exp Biol 1968;6:232-47.

5. Gunatilaka AA, Balasubramaniam S. Biological importance of some herbal medicines. J Nat Sci Council 1978;8:87-207.

6. Gamble JS. Flora of Presidency of Madras. London: Adlod and Sons Ltd; 1992. p. 170-1.

7. Harborne AJ. Phytochemical methods: A guide to modern techniques of plant analysis. J Nat Sci Council 2008;3:4-7.

8. Kokate CK, Purohit AP, Gokhale SB. Pharmacognosy. Pune: Nirali Prakashan; 2008. p. 56-8.

9. OECD Guidelines for the Testing of Chemicals. Available from: http:// www.oecd.org [Last accessed on 2016 Mar 20].

10. Zhang W, Zhao J, Wang J, Pang X, Zhuang X, Zhu X, et al. Hypoglycemic effect of aqueous extract of seabuckthorn (Hippophae rhamnoides L.) seed residues in streptozotocin-induced diabetic rats. Phytother Res 2010;24:228-32

11. Singh RK, Mehta S, Jaiswal D, Rai PK, Watal G. Antidiabetic effect of Ficus bengalensis aerial roots in experimental animals. J Ethnopharmacol 2009;123:110-4

12. Singh SK, Kesari AN, Gupta RK, Jaiswal D, Watal G. Assessment of antidiabetic potential of Cynodon dactylon extract in streptozotocin diabetic rats. J Ethnopharmacol 2007;114:174-9.

13. Si MM, Lou JS, Zhou CX, Shen JN, Wu HH, Yang B, et al. Insulin releasing and alpha-glucosidase inhibitory activity of ethyl acetate fraction of Acorus calamus in vitro and in vivo. J Ethnopharmacol 2010;128:154-9.

14. Ahmad W, Khan I, Khan MA, Ahmad M, Subhan F, Karim N, et al. Evaluation of antidiabetic and antihyperlipidemic activity of Artemisia indica Linn (aeriel parts) in streptozotocin induced diabetic rats. J Ethnopharmacol 2014;151:618-23.

15. $\mathrm{Xu} \mathrm{Z,} \mathrm{Ju} \mathrm{J,} \mathrm{Wang} \mathrm{K,} \mathrm{Gu} \mathrm{C,} \mathrm{Feng} \mathrm{Y.} \mathrm{Evaluation} \mathrm{of} \mathrm{hypoglycemic} \mathrm{activity}$ of total lignans from Fructus arctii in the spontaneously diabetic gotokakizaki rats. J Ethnopharmacol 2014;151:548-55.

16. Subhasree N, Kamella A, Kaliappan I, Agrawal A, Dubey GP. Antidiabetic and antihyperlipidemic activities of a novel polyherbal formulation in high fat diet/streptozotocin induced diabetic rat model. Indian J Pharmacol 2015;47:509-13.

17. Li Y, Huang TH, Yamahara J. Salacia root, a unique Ayurvedic medicine, meets multiple targets in diabetes and obesity. Life Sci 2008;82:1045-9.

18. Mohammadi J, Naik PR. Evaluation of hypoglycemic effect of Morus alba in an animal model. Indian J Pharmacol 2008;40:15-8.

19. Khanna AK, Chander R, Kapoor NK, Dhawan N. Hypolipidemic activity of picroliv in albino rats. Pytother Res 1994;8:403-7.

20. Lopes-Virella MF, Stone P, Ellis S, Colwell JA. Cholesterol determination in high-density lipoproteins separated by three different methods. Clin Chem 1977;23:882-4.

21. Carr TP, Andresen CJ, Rudel LL. Enzymatic determination of triglyceride, free cholesterol, and total cholesterol in tissue lipid extracts. Clin Biochem 1993;26:39-42.

22. Weggemans RM, Trautwein EA. Relation between soy-associated isoflavones and LDL and HDL cholesterol concentrations in humans: A meta-analysis. Eur J Clin Nutr 2003;57:940-6.

23. Kannadhasan R, Venkataraman S. Antidiabetic and antihyperlipidaemic activity of sedimental extract of Tinospora cordifolia in streptozotocin induced type 2 diabetes. Int J Pharm Pharm Sci 2012:520-7.

24. Aleykutty JD, Jyoti $H$. Effect of combination of two plant extracts on diabetes mellitus. Int J Pharm Pharm Sci 2018:49-52. 